\title{
BMJ Open Prevalence and correlates of sexual and gender-based violence against Chinese adolescent women who are involved in commercial sex: a cross-sectional study
}

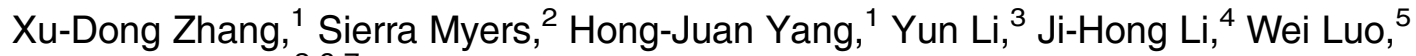 \\ Stanley Luchters ${ }^{2,6,7}$
}

To cite: Zhang X-D, Myers S, Yang H-J, et al. Prevalence and correlates of sexual and gender-based violence against Chinese adolescent women who are involved in commercial sex: a crosssectional study. BMJ Open 2016;6: 013409 .

doi:10.1136/bmjopen-2016013409

- Prepublication history for this paper is available online. To view these files please visit the journal online (http://dx.doi.org/10.1136/ bmjopen-2016-013409).

X-DZ and SM contributed equally.

Received 11 July 2016 Revised 2 November 2016 Accepted 3 November 2016

CrossMark

For numbered affiliations see end of article.

Correspondence to Dr Xu-Dong Zhang; zhangxudong@kmust.edu.cn

\section{ABSTRACT}

Objectives: Despite the vast quantity of research among Chinese female sex workers (FSWs) to address concerns regarding HIV/sexually transmitted infection (STI) risk, there is a paucity of research on issues of sexual and gender-based violence (SGBV) and the missed opportunity for sexual and reproductive health (SRH) promotion among young FSWs. Our research aimed to assess the prevalence and correlates of SGBV among Chinese adolescent FSWs, and to explore SRH service utilisation.

Design and methods: A cross-sectional study using a one-stage cluster sampling method was employed. A semistructured questionnaire was administered by trained peer educators or health workers. Multivariable logistic regression was conducted to determine individual and structural correlates of SGBV.

Setting and participants: Between July and September 2012, 310 adolescent women aged 1520 years, and who self-reported having received money or gifts in exchange for sex in the past 6 months were recruited and completed their interview in Kunming, Yunnan Province, China.

Results: Findings confirm the high prevalence of SGBV against adolescent FSWs in China, with 38\% $(118 / 310)$ of participants affected in the past year. Moreover, our study demonstrated the low uptake of public health services and high rates of prior unwanted pregnancy $(52 \%$; 61/118), abortion (53\%; 63/118) and self-reported STI symptoms (84\%; 99/ 118 ) in participants who were exposed to SGBV. Forced sexual debut was reported by nearly a quarter of FSWs (23\%; 70/310) and was independently associated with having had a drug-using intimate partner and younger age ( $<17$ years old) at first abortion. When controlling for potential confounders, having experienced SGBV was associated with frequent alcohol use, having self-reported symptoms of STI, having an intimate partner and having an intimate partner with illicit drug use.

Conclusions: This study calls for effective and integrated interventions addressing adolescent FSWs' vulnerability to SGBV and broader SRH consequences.

\section{Strengths and limitations of this study}

- To the best of our knowledge, this study is the first to provide a comprehensive description of prevalence and correlations of sexual and gender-based violence (SGBV) among adolescent female sex workers (FSW) in China.

- This study highlights the extensive burden of SGBV among adolescent sex workers, and the missed opportunity in addressing the unmet need for comprehensive sexual and reproductive health $(\mathrm{SRH})$ care.

- A close collaboration with FSW-led grassroots organisations facilitated the efficiency of recruitment and quality control. Data can serve to provide baseline information that can eventually be used for specific programme design and policymaking.

- The cross-sectional nature prevents the attribution of causality, thus there is a need for a longitudinal study to test these risk factors as true predictors of SGBV and related SRH outcomes.

- Further research is needed to obtain more detailed information on context and harmful levels of substance use and directly related SRH outcomes in this group, as well as the interaction between their male partners and their behaviours.

\section{BACKGROUND}

Sexual and gender-based violence among young female sex workers

Sexual and gender-based violence (SGBV) is a critical global concern and can lead to serious consequences in physical and psychological health and social well-being. ${ }^{1}{ }^{2}$ Globally, it is estimated $\sim 35 \%$ of women have experienced one or more encounters of SGBV in their lifetime, ${ }^{3}$ most often perpetrated by an intimate partner. ${ }^{4}$ Female adolescents are among the most vulnerable populations affected by SGBV with one in four participants experiencing sexual 
violence before the age of 18 years. ${ }^{5}$ A 2015 study showed that past-year prevalence of intimate partner violence (IPV) in participants aged 15-19 years and young women aged 20-24 years who live in low-income and middle-income countries was $26 \%$; the highest risks for past-year IPV to adolescent women was identified within specific nations in the Asia-Pacific and Latin America. ${ }^{6}$

Female sex workers (FSWs) have long been recognised as one of the key groups experiencing increased levels of SGBV which is associated with inconsistent or lack of condom use, and with increased risk of $\mathrm{HIV} /$ sexually transmitted infection (STI) infection. ${ }^{7}$ Violence also prevents them from accessing HIV information and services. $^{1-4}$ 8-12 In studies across India, Nepal and Thailand, young age at entry to sex work has been found to heighten vulnerability to physical and sexual violence victimisation, and relates to a twofold to fourfold increase in HIV infection. ${ }^{11}$ However, female adolescents and those who are involved in sex work have often been overlooked in global health and social policy. ${ }^{11} 13-15$

\section{Reproductive health challenges and constraints in China}

Adolescents aged 15-19 years represented almost $6 \%$ of the population in China in 2015. ${ }^{16}$ Increasing access to media, urbanisation and globalisation are contributing to changing sexual attitudes and behaviours, with more adolescent and young people engaging in premarital sex. ${ }^{17-20}$ However, policy responses in the country are lagging behind; although abortion has been legal in China since the early 1950s, governmental subsidised family planning services are generally only accessible to married couples. ${ }^{18} 1921$ Additionally, traditional sociocultural taboos regarding premarital sex and pregnancy, judgemental attitudes of health service providers, a lack of privacy at health facilities and limited access to comprehensive sex education in school settings, all contribute to low uptake of sexual and reproductive health (SRH) services and high rates of unwanted pregnancy and abortion among adolescent and young unmarried women in China. ${ }^{22-24}$ Currently, data of SGBV among Chinese adolescent women remains absent. ${ }^{6}$

In China, all forms of sex work are illegal and highly stigmatised; sex workers are often treated as quasicriminals and can receive administrative penalties of 15-day detention or fines. ${ }^{25}{ }^{26}$ Given their sexual risk behaviours and elevated risk of HIV/STI, FSWs have become a key population of China's HIV/STI prevention strategy since $2006 .{ }^{27}$ A national HIV surveillance system and government-led intervention programmes provide free HIV/syphilis/hepatitis B screening and care, condom promotion and health education services targeting FSWs across 31 provinces. $^{27-29}$ However, few HIV programmes deal with violence in a systematic way. Furthermore, ethical, legal and political constraints often contribute to the invisibility of adolescents in sex work and are often overlooked in intervention programmes. 113031
Despite the vast quantity of Chinese research targeting FSWs addressing HIV/STI risks, there is a paucity of research on SGBV and particularly the missed opportunity for SRH promotion among young FSWs. ${ }^{32}$ Lack of age-disaggregated data in existing FSWs' violence research also limits the understanding of SGBV issues faced by adolescents. A 2013 systematic review indicated that few epidemiological studies examined violence by intimate or other non-paying partners against sex workers. Also, no study examined drug use at the interpersonal-level or partner-level nature as risk factors linked to violence in the sex work context. ${ }^{33}$ Gathering data on violence-related SRH outcomes and risk factors is important in settings where such information is not available. In terms of supporting policymaking and intervention efforts, these data gaps must be met.

Our research aimed to assess the prevalence and correlates of SGBV, and to explore health service utilisation among Chinese adolescent FSWs.

\section{METHODS}

\section{Study setting and population}

Yunnan Province is a multiethnic area located in the 'Golden Triangle', a major international business and drug trafficking route, with a relatively high HIV-1 prevalence in China. ${ }^{34}$ Kunming, the capital city of Yunnan province, has over 6 million inhabitants including 3.1 million women. ${ }^{36}$ Kunming city proper includes four urban areas with $77 \%$ FSWs concentrated in these areas. $^{37}$

Our study was designed to enrol consenting women aged 15-19 years who self-reported to have received money or gifts in exchange for sex from one or more paying clients in the past 6 months, and are currently living in one of the four urban study sites of Kunming city. During recruitment, some adolescent FSWs had brought their closest colleagues of similar age (just exceeded 19 years) to accompany. To keep these valuable candidates in this study, the upper age limit was reset as 20 years. Enrolled FSWs aged 15-20 years are in this manuscript referred to as 'adolescent FSWs'.

\section{Study design}

This was a cross-sectional study using semistructured questionnaires in Chinese adopted questions regarding knowledge of family planning, knowledge of HIV/STI, sexual relationship and behaviour from the "WHO questionnaire for young people',38 and the 'Indonesia Demographic and Health Survey Questionnaire for Young Adult Reproductive Health'; ${ }^{39}$ some questions regarding SGBV and relationship control were also adopted from a cohort study of FSWs in Kenya. ${ }^{40}$ All three original instruments were tested for validity and reliability. We ran two pilot tests for the draft questionnaire among key informants (leaders of FSWs' support organisations/frontline doctors/senior peer educators/ outreach workers) and 14 adolescent FSWs. 


\section{Study procedures}

A detailed methodology of the study has been described elsewhere. ${ }^{41}$ In brief, the study was implemented in collaboration with Kunming-based, FSW-led, grassroots organisations and the district level Chinese Centres of Disease Control (CDC). A total of 101 locations in four urban districts of Kunming were identified as places where young FSWs frequently worked. A one-stage cluster sampling method was employed to recruit study participants between July and September 2012. The initial stage of sampling involved 27 clusters (locations), which were randomly selected from the 101 identified locations, proportionate to the total number of locations in each district. Potentially eligible women were recruited from these 27 clusters proportional to the total number of FSWs in each district until the required sample size was recruited.

Six peer educators (FSWs from local grassroots organisations) and six health workers (doctors/nurses selected from district level CDCs and hospitals) were trained as interviewers on the study procedures and questionnaire administration in a two-day workshop in Kunming. Using a semistructured questionnaire, face-to-face interviews were conducted at different entertainment venues selected from the sampling scheme. Collaboration between the research team, FSWs support organisations and the gatekeepers (managers or owners) of the entertainment venues facilitated the recruitment procedures: informal permission was obtained from the gatekeepers for arranging the appropriate space and time of interview, and for introducing potentially eligible participants. Interviews took between 40 and $50 \mathrm{~min}$ to complete.

\section{Study measures}

For the purpose of this study, the term 'sexual and gender-based violence' refers to any sex worker selfreporting an act of violence from an intimate male partner (husband, boyfriend or non-paying partner) or paying male clients, and which resulted in, or was likely to result in, physical, sexual harm or suffering to participants, whether occurring in the work place or in their private life. ${ }^{42-44}$ Participants were categorised into two groups as either having experienced SGBV in the past year or not and then questioned on whether they had been: 'pushed or shoved', 'slapped or hit by a thrown object', 'hit with a fist (or something else), kicked, or beaten', 'forced to do something sexual that was degrading/humiliating', 'robbed and hurt', and/or whether they had been 'forced to have sex'.

Any illicit drug use was defined as use of any heroin, cocaine, opium, marijuana, morphine, amphetaminetype stimulants, ketamine and/or ecstasy. Alcohol use was dichotomised as daily or usual-drinker (more than twice a week) versus abstainer or casual-drinker (once per week or less).

Inconsistent condom use was defined as not always using condoms in the past month, including when drunk or under the influence of drugs with intimate male partners and/or male clients.

Unwanted pregnancy was defined as ever having had a pregnancy that was not desired at the time the pregnancy was discovered.

\section{Data management and analysis}

Interviewers were paired and logical errors in the questionnaires were cross-checked on a daily basis. Paper-based data was double-entered using EpiData V.3.1 by trained staff. Identified discrepancies were corrected in line with the original questionnaires.

Statistical tests were performed using Stata V.11.0 (StataCorp, College Station, Texas, USA). Descriptive analysis was employed to characterise the participants. Pearson's $\chi^{2}$ tests and Wilcoxon rank sum tests were used to assess associations between sociodemographic variables and SGBV experience in the past year. Logistic regression analysis was applied to determine the exploratory variables, including sociodemographic characteristics, sex work characteristics, sexual behaviours, substance use and reproductive health characteristics most strongly associated with SGBV experience in the past year. Multivariate logistic regression models were adjusted for the exploratory variables found to be significantly associated $(\mathrm{p}<0.1)$ in the binary logistic regression analysis, and those hypothesised a priori to be associated using a stepwise forward-fitting approach beginning with the covariate with the lowest $p$ value. Multicollinearity has been identified for all exploratory variables before entered into multivariate analysis. Variables were considered significant with $\mathrm{p}<0.05$, and variables that did not markedly alter the model fit were removed from the model. The Akaike information criterion has been used as a measure of goodness-of-fit during the modelselection procedure, the multivariate model with the smallest value of Akaike information criterion was considered as the final model.

\section{Ethics}

All interviewers received training in research ethics, including non-judgmental interview skills and confidentiality. All participants were clearly informed about the study objectives, the confidential nature of information collected and their rights of voluntary involvement including refusing to answer questions and withdrawing. All participants provided their written informed consent before the interview. For those participants who were under the age of 18 years, a formal written informed consent was additionally obtained from an adult peer selected by the respective participant.

Two existing drop-in centres operated by FSW-led grassroots organisations provided an informal safe space, which victims of SGBV could attend for group or personal activities including medical treatment and peer support. The centres organised referral for clinical care services when indicated. 


\section{RESULTS}

A total of 378 adolescent FSWs were approached throughout all four urban areas of Kunming. Of these, 342 women $(90 \%)$ were eligible and consented to participate and $310(91 \%)$ completed the interview.

The mean self-reported age of the study participants was 19 years (IQR 18-20 years; table 1 ). Over half the participants were currently married or cohabiting $(53 \%$; $165 / 310)$ and lived predominantly with other sex workers or friends $(39 \% ; 122 / 310)$, or alone $(31 \%$; 96/ $310)$. Most sex workers came from outside of Kunming $(83 \% ; 257 / 310)$ and almost half $(46 \% ; 118 / 258)$ of these women arrived in Kunming within the past 12 months. The majority of the participants also reported that they had been a sex worker for $<6$ months $(62 \% ; 191 / 310)$. Over the past year, 82\% (255/310) of participants had an intimate partner, and most of these relationships were of short duration $(<1$ year).

Alcohol use was common with $83 \%$ of women (257/ 310) reporting drinking alcohol at least twice a week. As previously reported, ${ }^{41}$ inconsistent condom use in the past month with any male partner was reported by $57 \%$ of participants; $54 \%$ with male intimate partners and $65 \%$ with male clients. However, when we included the situation of under illicit drug use in this analysis, the rate of inconsistent condom use was sharply raised for approximately two-thirds of the women, and almost equal with male intimate partners $(65 \%)$ as with male clients (70\%; data not shown).

\section{Experience of SGBV in past year}

For 23\% (70/310) of participating women, their first sexual experience was one of forced sex. Thirty-eight per cent (118/310) of enrolled adolescent FSWs reported having experienced SGBV in the past year (table 2), with 88 women $(75 \%)$ reporting the perpetrator as their intimate male partner and 72 women $(62 \%)$ a male paying client. Of adolescent FSWs who were exposed to SGBV in the past year, approximately half (52\%; 61/118) reported to have had an unwanted pregnancy and 53\% (63/118) had ever had an induced abortion, while $84 \%(99 / 118)$ reported ever experiencing symptoms of STI in the past year.

\section{Correlates of SGBV}

Various factors were associated with having experienced SGBV in the past year (table 3). When controlling for potential confounders, adolescent FSWs experiencing SGBV in the past year were more likely to be frequent drinkers $\quad(\mathrm{AOR}=4.5 ; \quad 95 \% \mathrm{CI}$ 1.6-12.4), having a drug-using intimate partner ( $\mathrm{AOR}=2.3 ; 95 \%$ CI 1.1-4.5), having had an intimate male partner in the past year (AOR=13.2; 95\% CI=3.0-57.7) and having self-reported symptoms of STI in the past year $(\mathrm{AOR}=2.5$; 95\% CI $1.3-$ 4.9). In addition, although not statistically significant, women who experienced violence had a trend towards being younger and having used illicit drugs in the past year.
In our study, experiencing SGBV was independently associated with more frequent reports of unwanted pregnancy $(\mathrm{OR}=1.7 ; 95 \% \mathrm{CI} 1.1-2.7)$ and less likely to use of public health facilities $(\mathrm{OR}=2.1 ; 95 \%$ CI $1.3-3.5)$ or HIV testing services $(\mathrm{OR}=1.9$; 95\% CI 1.2-3.1) in binary logistic regression models.

\section{DISCUSSION}

To the best of our knowledge, this is the first study to describe the prevalence and patterns of SGBV and its correlates among adolescent FSWs in China. Our findings can serve to raise awareness of the prevalence and impact of these relatively hidden issues, and provide baseline information that can eventually be used for specific programme design and policymaking.

\section{The nature and magnitude of SGBV against adolescent FSW}

The data from this study reveal high rates $(38 \%)$ of reported SGBV against Chinese adolescent FSWs perpetrated by their intimate partners and/or paying clients in the past year. Although we have limited comparative information on rates of SGBV among the general population of young Chinese adolescents aged 15-17 years, the frequency of SGBV experienced by FSWs aged 1820 years in our study (38\%) is much higher than their Chinese adult counterparts (median age: 23, IQR: 1854) who ever had experienced lifetime forced sex $(14 \%) .{ }^{45}$ Reported SGBV in this study proved even higher than their same-aged peers exposed to recent physical or sexual violence in Thailand $(25 \%){ }^{8}$ These results are also higher than the Asia and Pacific regional pooled estimate of past-year IPV among adolescent women aged $15-19$ years $(28 \%){ }^{6}$ Evidence from this study indicates that adolescent FSWs are considerably more vulnerable to SGBV.

Similarly important, our findings reveal a remarkable confluence of SGBV threats from these adolescent women's intimate partners. Participants who are married, cohabiting or currently living with a male partner, had an intimate partner in the past year, or ever have had a drug-using intimate male partner were more likely to report SGBV. A cohort study with FSWs in Kenya suggested that the level of relationship control, particularly if those emotional partners dominate the drug supply and/or economic gains, can contribute to unwanted sex or difficulty in negotiating contraception. ${ }^{12}$ Individual-based, or group-based strategies that could be used to prevent SGBV perpetrated by intimate partners include: training workshops, peer education sessions, creation of safe spaces or improved referral services for clinical care. It is well-known that SGBV against FSWs has its roots in contextual factors such as criminalisation, migration, gender and economic inequities, work environments and stigma. ${ }^{33}$ In this regard, structural interventions become critical in tackling these underlying factors in China. 
Table 1 Sociodemographic, sex work, behavioural and reproductive health characteristics of adolescent female sex workers, stratified by sexual and gender-based violence experienced in the past year( $\mathrm{N}=310)$

\begin{tabular}{|c|c|c|c|c|}
\hline Characteristics & $\begin{array}{l}\text { All women } \\
(\mathrm{N}=310) \\
\mathrm{n}(\%)\end{array}$ & $\begin{array}{l}\text { No SGBV experienced } \\
\text { (past year) } \\
(\mathrm{N}=192 ; 62 \%) \\
\mathrm{n}(\%)\end{array}$ & $\begin{array}{l}\text { SGBV experienced } \\
\text { (past year) } \\
(\mathrm{N}=118 ; 38 \%) \\
n(\%)\end{array}$ & p Value* \\
\hline \multicolumn{5}{|l|}{ Sociodemographic variables } \\
\hline Age, median years (IQR) & $19(18-20)$ & $19(18-20)$ & $19(18-19)$ & $0.56 \dagger$ \\
\hline \multicolumn{4}{|l|}{ Education level } & 0.09 \\
\hline Illiterate or primary school only & $27(9)$ & $17(9)$ & $10(9)$ & \\
\hline Middle school & $228(73)$ & $148(77)$ & $80(68)$ & \\
\hline High school & $55(18)$ & $27(14)$ & $28(23)$ & \\
\hline \multicolumn{4}{|l|}{ Current marital status } & 0.031 \\
\hline Never married or single & $145(47)$ & $99(52)$ & $46(39)$ & \\
\hline Married or cohabiting & $165(53)$ & $93(48)$ & $72(61)$ & \\
\hline \multicolumn{4}{|l|}{ Currently living with } & 0.021 \\
\hline Parents or relatives & $17(6)$ & $8(4)$ & $9(8)$ & \\
\hline Male partner & $75(24)$ & $38(20)$ & 37 (31) & \\
\hline Other sex workers or friends & $122(39)$ & $77(40)$ & $45(38)$ & \\
\hline Alone & $96(31)$ & $69(36)$ & $27(23)$ & \\
\hline \multicolumn{4}{|l|}{ Place of birth } & 0.24 \\
\hline Kunming & $53(17)$ & $29(15)$ & $24(20)$ & \\
\hline Elsewhere & 257 (83) & $163(85)$ & $94(80)$ & \\
\hline \multicolumn{4}{|l|}{ Duration of living in Kunming (year) } & 0.60 \\
\hline$\leq 1$ & $118(46)$ & $73(45)$ & $45(48)$ & \\
\hline$>1$ & $140(54)$ & $91(55)$ & $49(52)$ & \\
\hline \multicolumn{5}{|l|}{ Sex work variables } \\
\hline $\begin{array}{l}\text { Median weekly number of male clients on } \\
\text { average (past month) (IQR) }\end{array}$ & $2(1-3)$ & $2(1-3)$ & $2(1-4)$ & $0.038 \dagger$ \\
\hline \multicolumn{4}{|l|}{ Duration in sex work } & 0.68 \\
\hline$\leq$ Half year & $191(62)$ & $120(63)$ & $71(60)$ & \\
\hline$>$ Half year & $119(38)$ & $72(37)$ & $47(40)$ & \\
\hline \multicolumn{4}{|c|}{ Average monthly income from sex work (past 3 months) $\ddagger \S$} & 0.037 \\
\hline$\leq € 360$ (low level) & $95(31)$ & $69(36)$ & $26(22)$ & \\
\hline$€ 361-720$ (middle level) & $146(47)$ & $84(44)$ & $62(53)$ & \\
\hline$>€ 720$ (high level) & $67(22)$ & $38(20)$ & $29(25)$ & \\
\hline \multicolumn{5}{|l|}{ Substance use variables } \\
\hline Any illicit drug use (PY)ף & $27(9)$ & $8(4)$ & $19(16)$ & $<0.001$ \\
\hline Any intimate male partner with illicit drug use & $59(19)$ & $20(10)$ & $39(33)$ & $<0.001$ \\
\hline \multicolumn{4}{|l|}{ Alcohol use $(P Y)^{\star \star}$} & $<0.001$ \\
\hline Abstainer or casual-drinker & $53(17)$ & $47(24)$ & $6(5)$ & \\
\hline Daily or usual-drinker & $257(83)$ & $145(76)$ & $112(95)$ & \\
\hline \multicolumn{5}{|l|}{ Sexual behavioural variables } \\
\hline Age at sex debut, median years (IQR) & $17(16-18)$ & $17(16-18)$ & $16.5(16-17)$ & $0.59 \dagger$ \\
\hline Had an intimate male partner (PY) & $255(82)$ & $139(72)$ & $116(98)$ & $<0.001$ \\
\hline \multicolumn{4}{|c|}{ Duration with the current/last intimate male partners } & $<0.001$ \\
\hline Never had an intimate male partner & $49(16)$ & $6(24)$ & $3(2)$ & \\
\hline Less than one year & $175(56)$ & $108(56)$ & $67(57)$ & \\
\hline Equal or more than one year & $86(28)$ & $38(20)$ & $48(41)$ & \\
\hline $\begin{array}{l}\text { Inconsistent condom use with any male } \\
\text { partners (past month) } \dagger \dagger\end{array}$ & $224(72)$ & $127(66)$ & $97(82)$ & 0.002 \\
\hline Currently using dual protection method $\ddagger \ddagger$ & $23(7)$ & $13(7)$ & $10(8)$ & 0.58 \\
\hline \multicolumn{5}{|l|}{ Reproductive health variables } \\
\hline Prior unwanted pregnancy & $135(44)$ & $74(39)$ & $61(52)$ & 0.023 \\
\hline \multirow[t]{2}{*}{ Prior abortion } & $136(44)$ & $73(38)$ & $63(53)$ & 0.008 \\
\hline & & & & Continued \\
\hline
\end{tabular}


Table 1 Continued

\begin{tabular}{|c|c|c|c|c|}
\hline Characteristics & $\begin{array}{l}\text { All women } \\
(\mathrm{N}=310) \\
\mathrm{n}(\%)\end{array}$ & $\begin{array}{l}\text { No SGBV experienced } \\
\text { (past year) } \\
(\mathrm{N}=192 ; 62 \%) \\
n(\%)\end{array}$ & $\begin{array}{l}\text { SGBV experienced } \\
\text { (past year) } \\
(\mathrm{N}=118 ; 38 \%) \\
\mathrm{n}(\%)\end{array}$ & p Value* \\
\hline Any self-reported symptom of STI (PY)§§ & $205(66)$ & $106(55)$ & $99(84)$ & 001 \\
\hline Usage of $\mathrm{r}$ & & & & \\
\hline Public health facilities & $193(65)$ & & & \\
\hline Unreliable health facilit & & & & 0.007 \\
\hline /sell-medication/ & & & & \\
\hline Received HIV testing (PY)††† & $140(45)$ & $98(51)$ & $42(36)$ & \\
\hline \multicolumn{5}{|c|}{ 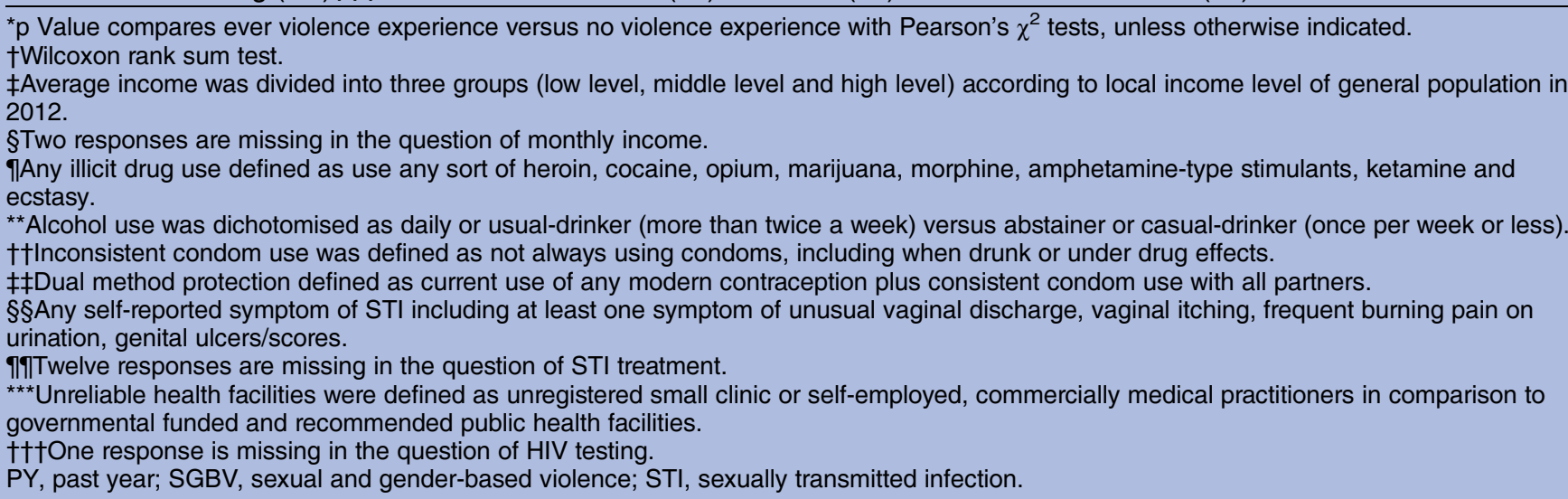 } \\
\hline
\end{tabular}

Table 2 Prevalence of sexual and gender-based violence in the past year among adolescent female sex workers $(\mathrm{N}=310)$

\begin{tabular}{|c|c|}
\hline Violence prevalence & $\mathrm{n} / \mathrm{N}(\%)$ \\
\hline Forced sex at sex debut & $70 / 310(23)$ \\
\hline $\begin{array}{l}\text { Sexual and gender-based violence by any } \\
\text { male partner (past year) }\end{array}$ & $118 / 310(38)$ \\
\hline $\begin{array}{l}\text { Sexual and gender-based violence by male } \\
\text { intimate partners }(P Y)^{\star}\end{array}$ & $88 / 118(75)$ \\
\hline $\begin{array}{l}\text { Physical violence (pushed, shoved, } \\
\text { slapped, hit, kicked or beaten) }\end{array}$ & $62 / 88(71)$ \\
\hline $\begin{array}{l}\text { Forced to have sex or to do something } \\
\text { sexual that was degrading/humiliating }\end{array}$ & $47 / 88(53)$ \\
\hline $\begin{array}{l}\text { Sexual and gender-based violence by } \\
\text { paying male partners (clients) }(P Y)^{\star}\end{array}$ & $72 / 118(61)$ \\
\hline $\begin{array}{l}\text { Physical violence (pushed, shoved, } \\
\text { slapped, hit, kicked or beaten) }\end{array}$ & $40 / 72(56)$ \\
\hline $\begin{array}{l}\text { Forced sex or to perform something } \\
\text { sexual that was degrading/humiliating }\end{array}$ & $37 / 72(51)$ \\
\hline Robbed and hurt & 24/72 (33) \\
\hline
\end{tabular}

Coerced or forced sexual initiation among young women has received limited attention in terms of research and HIV programming, despite the significant relationship with HIV risk among women in low-income and middle-income countries. ${ }^{46}$ Recent cross-regional meta-analyses revealed that forced sexual debut was the most prevalent in Africa at $21 \%$ for adolescent women aged $15-19$ years; ${ }^{6}$ our study confirms a similar prevalence of forced sexual debut among Chinese adolescent FSWs (23\%). These findings highlight both the global burden of forced sexual debut among adolescent women, and also underscore the intersections with risks, such as HIV/STI infection and unwanted pregnancies.

\section{Adverse sexual and reproductive health outcomes related to SGBV}

Similar to other studies, ${ }^{11} 122847$ our study documents that these adolescent FSWs who were exposed to SGBV are at risk for poorer SRH outcomes including high rates of unwanted pregnancy $(52 \%)$, abortion $(53 \%)$ and self-reported symptom of STI $(84 \%)$. Previously our study identified that only $50 \%$ of abortions were performed at safer health facilities, and, importantly, nearly three-quarters $(74 \%)$ of adolescent FSWs who reported undergoing an abortion had experienced complications from the procedure.

Similarly concerning, only $3 \%$ of participants had ever used long-acting reversible contraception, and currently using dual methods was reported by only $7 \%$ of adolescent FSWs. ${ }^{41}$ These findings indicate how tackling SGBV and related SRH risks might also help to reduce young women's risk and vulnerability to HIV/STI infection and unwanted pregnancy.

Globally, there is increasing evidence that integration of violence prevention initiatives for young women into $\mathrm{HIV} / \mathrm{STI}$, perinatal care and youth social development programmes, would be inexpensive and feasible, ${ }^{3}$ particularly when these infrastructures already exist, which is the case for China; meanwhile SGBV against FSWs is a 
Table 3 Sociodemographic, sex work, behavioural and reproductive health characteristics associated with sexual and gender-based violence experienced (by any male partner) in the past year among adolescent female sex workers $(\mathrm{N}=310)$

\begin{tabular}{|c|c|c|c|c|c|}
\hline \multirow[b]{2}{*}{ Variables } & \multicolumn{5}{|c|}{ Sexual and gender-based violence experience (past year) } \\
\hline & $\overline{\mathrm{n} / \mathrm{N}(\%)}$ & Crude OR (95\% Cl) & p Value & Adjusted OR* $(95 \% \mathrm{Cl})$ & p Value \\
\hline \multicolumn{6}{|l|}{ Sociodemographic variables } \\
\hline Age (years) & & 1.0 & & & \\
\hline $18-20$ & 97/257 (38) & 1.08 (0.59 to 1.99$)$ & 0.80 & & \\
\hline $15-17$ & $21 / 53(40)$ & & & & \\
\hline \multicolumn{6}{|l|}{ Current marital status } \\
\hline Never married or single & 46/145 (32) & 1.0 & & & \\
\hline Married or cohabiting & $72 / 165(44)$ & 1.67 (1.04 to 2.67$)$ & 0.031 & & \\
\hline \multicolumn{6}{|l|}{ Currently living with } \\
\hline Alone & $27 / 96(28)$ & 1.0 & & & \\
\hline Other sex workers or friends & $45 / 122(37)$ & 1.49 (0.84 to 2.67$)$ & 0.17 & & \\
\hline Male partner & $37 / 75(49)$ & 2.49 (1.30 to 4.77$)$ & 0.005 & & \\
\hline Parents or relatives & 9/17 (53) & 0.34 (0.98 to 8.43$)$ & 0.044 & & \\
\hline \multicolumn{6}{|l|}{ Sex work variables } \\
\hline \multicolumn{6}{|l|}{ Monthly income from sex work on average (past 3 months) $\dagger$} \\
\hline$\leq € 360$ (low level) & 26/95 (27) & 1.0 & & & \\
\hline$€ 361-720$ (middle level) & $62 / 146(43)$ & 1.96 (1.11 to 3.45$)$ & 0.017 & & \\
\hline$>€ 720$ (high level) & 29/67 (43) & $2.03(1.03$ to 3.97$)$ & 0.036 & & \\
\hline Weekly number of male clients on average (past month) $\ddagger$ & & & & & 0.16 \\
\hline$\leq 2$ & $61 / 189(32)$ & 1.0 & & 1.0 & \\
\hline 3 or more & $57 / 121(47)$ & $1.87(1.16$ to 3.01$)$ & 0.009 & 1.49 (0.86 to 2.58$)$ & \\
\hline \multicolumn{6}{|l|}{ Substance use variables } \\
\hline Any illicit drug use (PY)‡ & & & & & 0.15 \\
\hline No & 99/283 (35) & 1.0 & & 1.0 & \\
\hline Yes & 19/27 (70) & $4.41(1.83$ to 10.69$)$ & $<0.001$ & $2.10(0.76$ to 5.78$)$ & \\
\hline Any intimate male partner with illicit drug use $\ddagger$ & & & & & 0.02 \\
\hline No & $79 / 251(31)$ & 1.0 & & 1.0 & \\
\hline Yes & $39 / 59(66)$ & 4.25 (2.27 to 7.95$)$ & $<0.001$ & 2.25 (1.14 to 4.46$)$ & \\
\hline \multicolumn{6}{|l|}{ Alcohol use (PY) } \\
\hline Abstainer or casual drinker & 6/53 (11) & 1.0 & & 1.0 & 0.004 \\
\hline Drinks daily or frequently & $112 / 257(44)$ & $6.05(2.42$ to 15.11$)$ & $<0.001$ & 4.50 (1.63 to 12.42$)$ & \\
\hline \multicolumn{6}{|l|}{ Sexual behavioural variables } \\
\hline \multicolumn{6}{|l|}{ Had an intimate male partner (PY)‡ } \\
\hline No & 2/55 (4) & 1.0 & & 1.0 & 0.001 \\
\hline Yes & $116 / 255(46)$ & 22.12 (4.84 to 101.14$)$ & $<0.001$ & 13.20 (3.02 to 57.74$)$ & \\
\hline Inconsistent condom use with any male partners & $25 / 74(34)$ & & & & \\
\hline No & $71 / 137$ (52) & 1.0 & & & \\
\hline \multirow[t]{2}{*}{ Yes } & & 2.36 (1.34 to 4.17$)$ & 0.002 & & \\
\hline & & & & & Continued \\
\hline
\end{tabular}




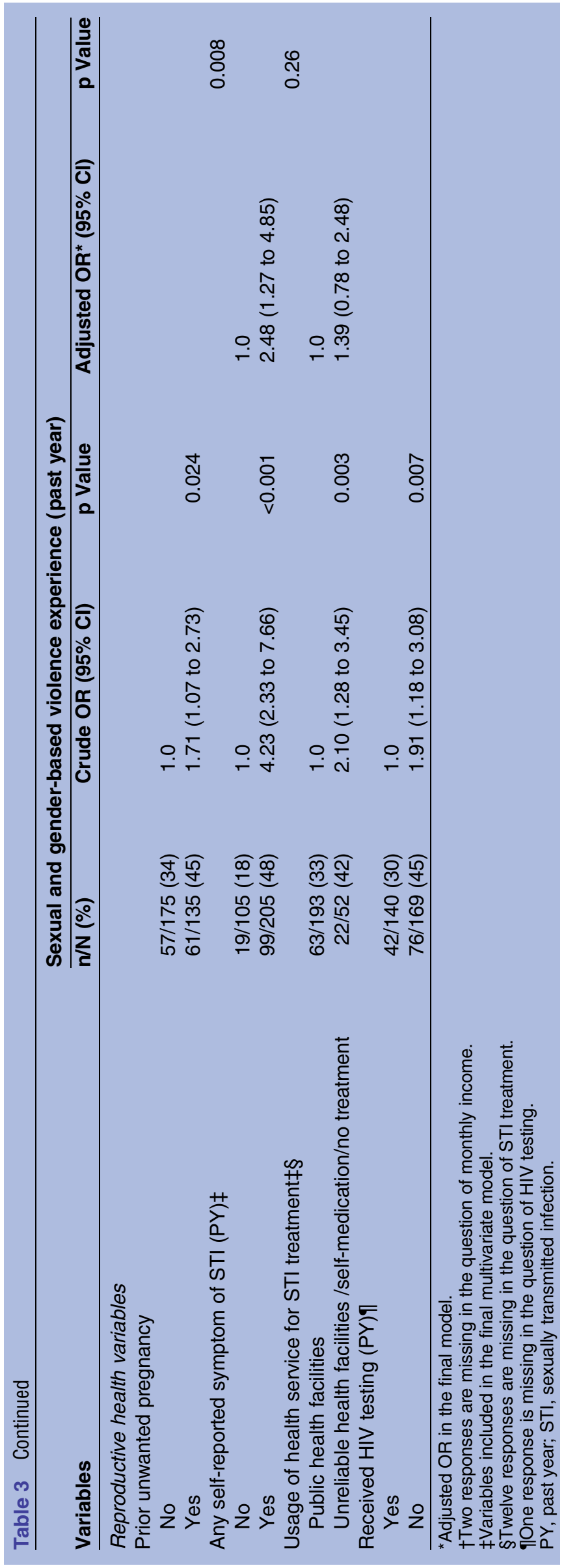

pervasive and complex issue which requires inputs from multiple sectors including the community, health, police and legal sectors. In this regard, integrated multisectoral and multicomponent interventions need to be developed to address both violence and broader SRH risks, and delivered through these existing platforms.

\section{Substance use and unsafe sex associated with SGBV}

More specifically, our study noted two important risk factors for SGBV. Daily or frequent alcohol consumption and drug use were both associated with SGBV in adolescent FSWs. We also found evidence regarding the influence of illicit drug use on condom use. Our data showed that these drug-using participants were more likely to have heightened inconsistent condom use with both clients and intimate partners than non-drug using adolescent FSWs. These findings are consistent with previous studies among adult Chinese FSWs which have shown the association between alcohol intoxication (AOR=1.87; 95\% CI 1.31-2.65), drug use (AOR=1.99; 95\% CI 1.36-2.91) and violence perpetrated by clients. $^{7}{ }^{10}$ In addition to these two risk factors, we found that the majority of adolescent FSWs with SGBV experience $(82 \%)$ reported inconsistent condom use with male partners.

The triple jeopardy for adolescent FSW of SGBV, unsafe sex and substance use found in this study has also been identified as a neglected, yet pressing issue in the Global Burden of Disease Study 2013. ${ }^{48}$ This study brought to light that unsafe sex is the most significant risk factor for disability-adjusted life-years (DALYs) lost for adolescents aged 15-19 years, meanwhile IPV is ranked the third leading risk of DALYs lost; for Chinese young people aged 20-24 years old, alcohol misuse and drug use disorders were the highest risk factors of DALYs lost. China has taken compulsory actions against illicit drug users including incarceration at compulsory detoxification centres for up to 2 years or mandatory treatment in the community for up to 3 years. ${ }^{49}$ Official data showed that almost three quarters $(73 \%)$ of registered illicit drug users were between the ages of 16 to 25 years in $2011 .^{50}$ It is crucial for governmental policymakers and health professionals to take the burden of disease and risk factors shown here into consideration in further actions affecting this vulnerable group during this important period stage of life. In some cases, there is a need to design and implement harm reduction projects and services specifically for adolescent FSWs involved in risky substance use as mainstream programmes do no appropriately address the needs of this population.

\section{Missed opportunity to address SGBV and related SRH problem}

In China, powered by urbanisation and industrialisation, rural-to-urban migrant numbers have increased sharply since the 1980s; $64 \%$ of the female migrants between the ages 15 and 24 years old. ${ }^{51}$ Existing evidence 
suggests that the adolescent and young migrant women engaged in commercial sex are not a small population in China. ${ }^{45}{ }^{52-54}$ Our findings demonstrate that most of the participants $(83 \%)$ in this study were domestic migrants and had low educational attainment. Adolescent FSWs exposed to SGBV were more likely to report STI symptoms, and were less likely to use public health facilities for STI treatment and HIV testing. Lack of insurance coverage, government-subsidised family planning services that are only available for married women, and the compounding vulnerabilities of younger age, immigration situation, stigma and illegal status of sex work, all add to the significant barriers in accessing SRH services for this group. ${ }^{56}$ Moreover, our previous findings showed that just 27\% adolescent FSWs reported ever having received any SRH education from health providers. ${ }^{41}$

The cumulative evidence from our study highlights a critical missed opportunity for the public health sector to address SGBV and related SRH issues. The public health system is a key entry point for women to receive integrated services, but, healthcare providers and others working with FSWs should be trained in counselling and service provision targeted at this specific population. WHO is currently developing a global plan of action to strengthen the role of the health system in addressing interpersonal violence, particularly against women and children, ${ }^{3}$ which is expected to provide an important framework for country strategies.

Importantly, due to the experience from the precommunication, instrument development, recruitment process and follow-up support services given during this study, we emphasise that FSW or women-led community-based organisations have a distinct advantage in being able to reach and build relationships with this population at a grassroots level. Population networks and the wider civil society are crucial for successfully delivering services to them, and must be invested in. At the end of July 2015, a new fund for HIV/AIDS Prevention was established by the Chinese government, ${ }^{57}$ which specifically encourages a greater involvement of all levels of civil society organisations in HIV/ AIDS prevention and care for key populations, including men who have sex with men, drug users, FSWs and people living with HIV/AIDS; it is identified as an opportunity for tailored interventions to be led by grassroots organisations which may better meet adolescent FSWs' needs and address SGBV.

\section{Limitation and priorities for further research}

Our study has several limitations. The cross-sectional nature prevents the attribution of causality, thus there is a need for a longitudinal study to test these risk factors as true predictors of SGBV and related SRH outcomes. Given the severe penalties for illicit drug use, fear of disclosure of illicit drug use may have resulted in an underestimation of the prevalence of drug use and drug-using partners; further research is needed to obtain more detailed information on the context and harmful levels of substance use and directly related SRH outcomes, as well as the interaction between their male partners and their behaviours. Additional qualitative studies would be useful to offer reliable explanations and a better understanding of behaviours and SRH needs.

\section{CONCLUSIONS}

Operational research on integrated interventions to prevent or reduce SGBV against adolescent FSWs is urgently needed; for transferring knowledge to action, and for evaluating the effectiveness of this approach and providing evidence-based recommendations.

The evidence presented here shows extensive SGBV against adolescent FSWs in China. Our findings indicate that SRH risk, poor SRH outcomes and substance use are significant health issues among adolescent FSWs exposed to SGBV; meanwhile the missed opportunity of unmet need for comprehensive SRH care is identified in this group. At minimum, the national policymakers need to take steps to ensure that this marginalised and underserved population has equal access to the existing services. Effective interventions targeting adolescent FSW vulnerability to SGBV and adverse SRH consequences are crucial and complement the UNiTE to End Violence against Women Campaign,${ }^{58}$ while also contributing to the Sustainable Development Goals 1-12, 16 and UNICEF's and UNAIDS' 'All In' initiative to end the AIDS epidemic among adolescents by $2030 .^{59}$ The 2015 Global Strategy for Women's Children's and Adolescents Health requires a responsive health system to ensure their healthy development, but it also requires a focus on social structural factors including the legal and policy environment which greatly impact the effectiveness of programme initiatives for FSW and adolescent health. ${ }^{11} 134155566061$ Of note, the illicit drug use was examined as an important risk factor associated with SGBV in our study. Specialist interventions that address alcohol and illicit drug use can help to tackle SGBV, or carrying out advocacy activities to ensure that those in this subgroup of FSWs know that SRH and harm reduction services exist. This will help improve the equity of health and well-being services for adolescent FSWs in China.

\section{Author affiliations}

${ }^{1}$ Yunnan Research Centre for Hygiene and Health Management, School of Management and Economics, Kunming University of Science and Technology, Kunming, China

${ }^{2}$ Burnet Institute, Melbourne, Victoria, Australia

${ }^{3}$ The Affiliated Hospital, Kunming University of Science and Technology, Kunming, China

${ }^{4}$ Kunming Maternal and Child Health Care Centre, Kunming, China

${ }^{5}$ Sexually Transmitted Disease Unit, Kunming Centre for Disease Control, Kunming, China

${ }^{6}$ Department of Obstetrics and Gynaecology, International Centre for Reproductive Health, Ghent University, Ghent, Belgium

${ }^{7}$ Department of Epidemiology and Preventive Medicine, School of Public Health and Preventive Medicine, Monash University, Victoria, Australia 
Contributors XZ designed and implemented the study, conducted data collection and analysis. XZ and SM wrote the first draft of the manuscript. SL participated in the design of the study, contributions to interpretation of the findings and final review. HY, YL, JL and WL coordinated the study and commented on the revisions. All authors critically reviewed the manuscript, contributed to its revision and approved the final version.

Funding This research was financially and technically supported by National Natural Sciences Foundation of China (71463034; Hong-Juan Yang, PI) and Yunnan Provincial Scientific and Innovative Research Scheme (2016DH001; Wei $\mathrm{Li}, \mathrm{PI}$ ). The authors gratefully acknowledge the contribution to this work of the Victorian Operational Infrastructure Support Programme received by the Burnet Institute. Funding was provided by the National Health and Medical Research Council of Australia (NHMRC) (Career Development Fellowship to Stanley Luchters).

Competing interests None declared.

Ethics approval Ethics approval for this research study was obtained from the Ethics Committee of Kunming Public Health Bureau for the study protocol, informed consent forms, information sheets and for any subsequent modifications.

Provenance and peer review Not commissioned; externally peer reviewed.

Data sharing statement No additional data are available.

Open Access This is an Open Access article distributed in accordance with the Creative Commons Attribution Non Commercial (CC BY-NC 4.0) license, which permits others to distribute, remix, adapt, build upon this work noncommercially, and license their derivative works on different terms, provided the original work is properly cited and the use is non-commercial. See: http:// creativecommons.org/licenses/by-nc/4.0/

\section{REFERENCES}

1. WHO. Addressing violence against sex workers. http://www.who.int/ hiv/pub/sti/sex_worker_implementation/swit_chpt2.pdf

2. Temmerman $M$. Research priorities to address violence against women and participants. Lancet 2015;385:e38-40.

3. The Lancet. Violence against women and participants: how far have we come? 2015;386:2029.

4. WHO. Violence against women: intimate partner and sexual violence against women. http://apps.who.int/iris/bitstream/10665/112325/1/ WHO RHR 14.11 eng.pdf

5. Centers for Disease Control and Prevention. Sexual violence: facts at a glance. http://www.cdc.gov/violenceprevention/pdf/ sv-datasheet-a.pdf

6. Decker MR, Latimore AD, Yasutake S, et al. Gender-based violence against adolescent and young adult women in low- and middle-income countries. J Adolesc Health 2015;56:188-96.

7. Hong $\mathrm{Y}$, Zhang C, Li X, et al. Partner violence and psychosocial distress among female sex workers in China. PLOS ONE 2013;8: e62290

8. Decker MR, McCauley HL, Phuengsamran D, et al. Sex trafficking sexual risk, sexually transmitted infection and reproductive health among female sex workers in Thailand. J Epidemiol Community Health 2011;65:334-9.

9. Sherwood JA, Grosso A, Decker MR, et al. Sexual violence against female sex workers in the Gambia: a cross-sectional examination of the associations between victimization and reproductive, sexual and mental health. BMC Public Health 2015;15:270

10. Zhang C, Li X, Su S, et al. Violence against Chinese female sex workers from their stable partners: a hierarchical multiple regression analysis. Healthcare Women Int 2015;36:797-815.

11. Silverman JG. Adolescent female sex workers: invisibility, violence and HIV. Arch Dis Child 2011;96:478-81.

12. Luchters S, Richter ML, Bosire W, et al. The contribution of emotional partners to sexual risk taking and violence among female sex workers in Mombasa, Kenya: a cohort study. PLoS ONE 2013;8 e68855.

13. Patton GC, Sawyer SM, Santelli JS, et al. Our future: a Lancet commission on adolescent health and well-being. The Lancet 2016;387:2423-78.

14. Bruce J. A note on the social and economic development and reproductive health of vulnerable adolescent participants. Florence, Italy: United Nations Division for the Advancement of Women (DAW), 2006.
15. Bruce J. Participants left behind: redirecting HIV interventions toward the most vulnerable. New York, USA: Population Council, 2007.

16. Department of Economic and Social Affairs, Population Division of United Nations. World population prospects: the 2015 revision. https://esa.un.org/unpd/wpp

17. Zhou Y, Xiong C, Xiong J, et al. A blind area of family planning services in China: unintended pregnancy among unmarried graduate students. BMC Public Health 2013;13:198.

18. Qian X, Tang S, Garner P. Unintended pregnancy and induced abortion among unmarried women in China: a systematic review. BMC Health Serv Res 2004;4:1.

19. Cheng Y, Guo X, Li Y, et al. Repeat induced abortions and contraceptive practices among unmarried young women seeking an abortion in China. Int J Gynecol Obstet 2004;87:199-202.

20. Zheng X-Y, Chen G, Han Y-L, et al. Survey of youth access to reproductive health in China. Popul Dev 2010;16:2-16. [in Chinese].

21. Tu X, Cui N, Lou C, et al. Do family-planning workers in China support provision of sexual and reproductive health services to unmarried young people? Bull World Health Organ 2004;82: 274-80.

22. Hu Y-K, Zheng $X-Y$, Cheng $G$. Sexual and reproductive health of Chinese youth is urgently needed to put on the policy agenda. $J$ Int Reprod Health Fam Plan 2010;29:392-6. [in Chinese].

23. Mao Z-Y. Consideration on abortion among adolescents in China. Northwest Population 2011;32:95-8. [in Chinese].

24. Burki T. Sex education in China leaves young vulnerable to infection Lancet Infect Dis 2016;16:26.

25. United Nations Development Programme. Sex work and the law in Asia and the Pacific. Bangkok, Thailand: UNDP Asia-Pacific Regional Centre, 2012.

26. Kendall M. China: Sex work and HIV. http://aidsdatahub.org/ dmdocuments/sex work hiv china.pdf

27. Ministry of Health of the People's Republic of China. Guidelines for intervention towards high risk behavior in relation to HIV/AIDS. Beijing: Ministry of Health of the People's Republic of China, 2005.

28. Poon AN, Li Z, Wang N, et al. Review of HIV and other sexually transmitted infections among female sex workers in China. AIDS Care 2011;23:5-25

29. Wen L, Chen S, Seguy N, et al. Is the HIV sentinel surveillance system adequate in China? Findings from an evaluation of the national HIV sentinel surveillance system. Western Pac Surveill Response J 2012;3:78-85.

30. Zhang X-D, Temmerman M, Li Y, et al. Vulnerabilities, health needs and predictors of high-risk sexual behaviour among female adolescent sex workers in Kunming, China. Sex Transm Infect 2013;89:237-44.

31. McClure C, Chandler C, Bissell S. Responses to HIV in sexually exploited children or adolescents who sell sex.

32. Darroch JE, Singh S, Woog V, et al. Research gaps in adolescent sexual and reproductive health. https://www.guttmacher.org/report/ research-gaps-in-sexual-and-reproductive-health

33. Deering KN, Amin A, Shoveller J, et al. A systematic review of the correlates of violence against sex workers. Am J Public Health 2014;104:e42-54

34. Duan S, Shen S, Bulterys M, et al. Estimation of HIV-1 incidence among five focal populations in Dehong, Yunnan: a hard hit area along a major drug trafficking route. BMC Public Health 2010;10:180.

35. Peng Z-H, Cheng Y-J, Reilly KH. Spatial distribution of HIV/AIDS in Yunnan province, People's Republic of China. Geospatial Health 2011;5:177-82.

36. Yunnan Statistics Bureau. Yunnan 2010 report of sixth population census. http://www.stats.yn.gov.cn/TJJMH_Model/newsview.aspx? $\mathrm{id}=1598421$

37. Li L, Chen L, Yang Y. Population estimation, HIV/AIDS knowledge awareness and risk behaviour among female sex workers in Kunming, Yunnan. J Dermatol Venereol 2009;31:1-2 [in Chinese].

38. World Health Organization. WHO Survey Questionnaire for Young People. http://www.who.int/reproductive-health/adolescent/ Adolescent_core_instruments.en.html

39. Badan Pusat Statistik (BPS)-Statistics Indonesia. The Indonesia DHS Survey 2007: Young Adult Reproductive Health Survey Questionnaire. http://dhsprogram.com/pubs/pdf/FR219/FR219.pdf

40. Luchters S, Sarna A, Geibel S, et al. Safer Sexual behaviors after 12 months of antiretroviral treatment in Mombasa, Kenya: a prospective cohort. AIDS Patient Care STDS 2008;22:587-94.

41. Zhang XD, Lim MS, Zhang XD, et al. Sexual and reproductive health knowledge, family planning uptake, and factors associated with unmet need for modern contraception among adolescent female sex workers in Kunming, China. PLoS ONE 2015;10:e0115435.

42. WHO. World report on violence and health. Geneva: WHO, 2002. 
43. United Nations General Assembly. Declaration on the elimination of violence against women. 1993. http://www.un.org/documents/ga/res/ 48/a48r104.htm

44. United Nations Entity for Gender Equality and the Empowerment of Women. Convention on the elimination of all forms of discrimination against women. 1999. http://www.un.org/womenwatch/daw/cedaw/ recommendations/recomm htm

45. Kelvin EA, Sun X, Mantell JE, et al. Vulnerability to sexual violence and participation in sex work among high-end entertainment centre workers in Hunan Province, China. Sex Health 2013;10:391-9.

46. Stockman JK, Lucea MB, Campbell JC. Forced sexual initiation, sexual intimate partner violence and HIV risk in women: a global review of the literature. AIDS Behav 2013;17:832-47.

47. Okal J, Chersich MF, Tsui S, et al. Sexual and physical violence against female sex workers in Kenya: a qualitative enquiry. AIDS Care 2011;23:612-8.

48. Mokdad AH, Forouzanfar MH, Daoud F, et al. Global burden of diseases, injuries, and risk factors for young people's health during 1990-2013: a systematic analysis for the Global Burden of Disease Study 2013. Lancet 2016;387:2383-401.

49. Kamarulzaman A, McBrayera JL. Compulsory drug detention centers in East and Southeast Asia. Int J Drug Policy 2015;26(Suppl 1):S33-7.

50. China National Narcotics Control Commission (NNCC). Annual Report on Drug Control in China 2013. Beijing, 2013.

51. UNFPA. Domestic migrants in China-Facts and figures 2010 Beijing: UNFPA China, 2010.

52. Sudhinaraset M, Astone N, Blum RW. Migration and Unprotected Sex in Shanghai, China: correlates of condom use and contraceptive consistency across migrant and non-migrant youth. J Adolesc Health 2012;50:S68-74.
53. Fan C. Rural-urban migration and gender division of labor in transitional China. Int J Urban Reg Res 2003;27:24-47.

54. Yang X, Xia G. Gender, migration, risky Sex, and HIV infection in China. Stud Fam Plann 2006;37:241-50.

55. Zhang XD, Kelly-Hanku A, Chai JJ, et al. Sexual and reproductive health risks among female adolescents who use amphetamine-type stimulants and sell sex: a qualitative inquiry in Yunnan, China. Harm Reduct J 2015;12:34.

56. Zhang XD, Kennedy E, Temmerman M, et al. High rates of abortion and low levels of contraceptive use among adolescent female sex workers in Kunming, China: a cross-sectional analysis. Eur J Contracept Reprod Healthcare 2014;19: 368-78.

57. The National Health and Family Planning Commission of China (NHFPC). Notice on the establishment of the fund for HIV/AIDS prevention by social organizations. Beijing: NHFPC 2015.

58. The United Nations. The United Nations Secretary-General's UNiTE to End Violence against Women campaign. http://www.un.org/en/ women/endviolence/about.shtml

59. UNAIDS. [Joint UN Programme on HIV/AIDS] and UNICEF. UN launches 'All In' initiative to end adolescent AIDS. http://www.un.org/ sustainabledevelopment/blog/2015/02/un-launches-initiativeend-adolescent-aids/

60. Cortina J, Taran P, Raphael A. Adolescent and young women migrants. http://www.globalmigrationgroup.org/sites/default/files/ 7._Chapter_4.pdf

61. Temmerman M, Khosla R, Bhutta ZA, et al. Towards a new Global Strategy for Women's, Children's and Adolescents' Health. BMJ 2015;351:h4414. 